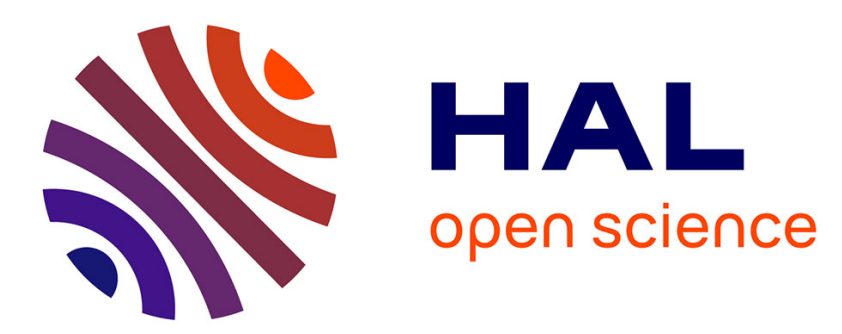

\title{
Magnetic Reversal of In-Plane Anisotropic Garnet Films: Orientational Phase Transition Isolines
}

S. Lebedev

\section{To cite this version:}

S. Lebedev. Magnetic Reversal of In-Plane Anisotropic Garnet Films: Orientational Phase Transition Isolines. Journal de Physique IV Proceedings, 1997, 07 (C1), pp.C1-731-C1-732. 10.1051/jp4:19971299 . jpa-00255065

\section{HAL Id: jpa-00255065 https://hal.science/jpa-00255065}

Submitted on 1 Jan 1997

HAL is a multi-disciplinary open access archive for the deposit and dissemination of scientific research documents, whether they are published or not. The documents may come from teaching and research institutions in France or abroad, or from public or private research centers.
L'archive ouverte pluridisciplinaire HAL, est destinée au dépôt et à la diffusion de documents scientifiques de niveau recherche, publiés ou non, émanant des établissements d'enseignement et de recherche français ou étrangers, des laboratoires publics ou privés. 


\title{
Magnetic Reversal of In-Plane Anisotropic Garnet Films: Orientational Phase Transition Isolines
}

\author{
S.V. Lebedev \\ Laboratory of Applied Magnetooptics, MEPhI, Kashirskoe shosse, 115409 Moscow, Russia
}

\begin{abstract}
The results of experimental investigation of longitudinal hysteresis of epitaxial garnet films with "easy axis in plane" anisotropy using magnetooptical method are presented. The orientational phase transition isolines corresponding to change in magnetic reversal mechanisms at room $(T=293 \mathrm{~K}$ ) and near liquid nitrogen ( $T=90 \mathrm{~K}$ ) temperatures are obtained by vistual observation along easy axis of magnetization. It is shown that the regions of horizontal and sloped domains motion [1] are separated with certain interval of monodomain state that increases with increasing of transversal magnetizing. The threshold nature of sloped domains appearance is demonstrated.
\end{abstract}

\section{INTRODUCTION}

With this work we continue a series of investigations of magnetic reversal processes of epitaxial garnet films with "easy axis in plane" anisotropy [1-3]. The objective here is the detailed investigation of longitudinal hysteresis along easy axis of magnetization with obtaining quantitative results regarding changes in magnetic reversal mechanisms described earlier [1]. All experiments were carried out both at room $(T=293 \mathrm{~K})$ and cryogenic $(T=90 \mathrm{~K})$ temperatures. The low-temperature part of investigation seems to be very important because of the possibility of practical using of such films both in binary structures "high temperature super conducting /HTSC/ film - garnet film" to create a new class of IR bolometers [4] and as a new instrument for investigations of HTSC samples themselves [5].

\section{EXPERIMENTAL SETUP DETAILS}

We have used the same epitaxial garnet $(\mathrm{BiLuCa})_{3}(\mathrm{FeGe})_{5} \mathrm{O}_{12}$ films, grown on a (111)-oriented $\mathrm{Gd}_{3} \mathrm{Ga}_{5} \mathrm{O}_{12}$ single crystal substrate, as in [1-3]. The cryogenic temperature was chosen to be $90 \mathrm{~K}$ because this value is the same for diamagnetic transition of the most HTSC films of YBaCuO at low magnetic fields.

Some peculiarities of experimental setup and technique as compared with those reported in [1] are caused by low-temperature investigations where the optical cryostat was used. The cooling of magnetooptical film up to given temperature was achieved by means of its pressing to the copper heat-sink of optical cryostat. The known prism-type magnetooptical converter was used to input-output light emission (fig.1). The epitaxial structure was bonded with immersion liquid to the hypotenuse side of right triangle glass prism. In this optical geometry the light undergoes the total internal reflection on the "garnet-vacuum" interface that permits the uniform cooling of garnet film contacted with polished heat-sink or, in perspective, with HTSC sample. While passing through the garnet the light interacts with its planar magnetization due to Faraday effect. The rotation of plane of polarization is propotional to sample magnetization and is detected by ordinary photodiode scheme placed after output analyzer. Special measures were undertaken to ensure uniform and loose contact of garnet film with heat-sink in order to avoid the modification of

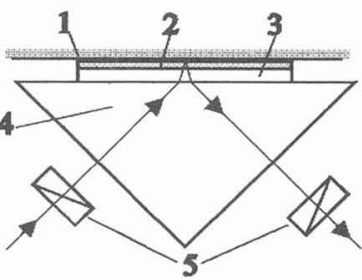

1 - heat-siok;

2- gamet film;

3 - substrate;

4- glass prism;

5-polarizers

Figure 1: Magnetooptical converter own domain structure and hysteresis through magnetostriction. 


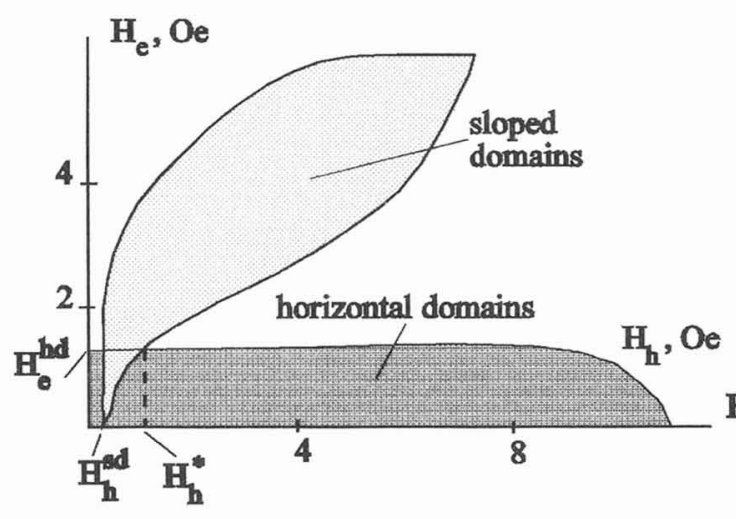

a)

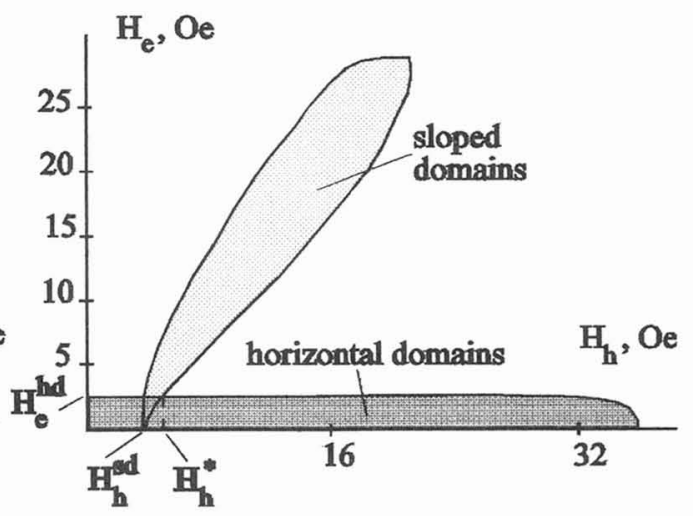

b)

Figure 2: Orientational phase transition isolines at room (a) and cryogenic (b) temperatures

\section{EXPERIMENTAL RESULTS}

The room temperature dynamics of longitudinal hysteresis along easy axis of magnetization and by changing of transversal magnetizing $\mathrm{H}_{\mathrm{h}}$ (the field directed along hard axis) was presented earlier [2]. More detailed investigation shows that starting from transversal magnetic field $\mathrm{H}_{\mathrm{h}}{ }^{*}$ the regions of horizontal and sloped domains motion [1] are separated with certain interval of monodomain state that increases with increasing of transversal magnetizing (fig. 2a). The disappearance of horizontal domains was determined to be the only process resulting in point of inflection on the hysteresis curve. In spite of existence of another two orientational phase transition points (from intermediate monodomain state to sloped domains and from those to final monodomain) there are no visible qualitative changes in hysteresis curve.

Fig. 2 displays the orientational phase transition isolines corresponding to the change in magnetic reversal mechanism plotted on field coordinates $\left(\mathrm{H}_{\mathrm{e}}\right.$ - magnetic field directed along easy axis) at room (a) and cryogenic (b) temperatures. By means of painting we indicate the regions with primary domain-wall motion, the unlined field area remains monodomain. It is to note that at transversal magnetizing lower than monodomain point $\mathrm{H}_{h}{ }^{*}$ there is a small interval where the horizontal and sloped domains exist simultaneously. The lower border of this interval $\mathrm{H}_{\mathrm{h}}{ }^{\text {sd }}$ is about $0.1-0.2 \mathrm{Oe}$. One more important detail is the constancy of $\mathrm{H}_{e}^{\text {hd }}$ - longitudinal magnetic field of horizontal domains disappearance.

The cooling of garnet film doesn't result in any qualitative change of magnetic anisotropy, magnetization structure or main features of hysteresis curve. All characteristic fields including the coercivity of the garnet film increase several times. In addition the visual observation shows that at room temperature magnetizing the appearance and growth of inverse magnetic domains occurs at sample edges, while after cooling it takes place mostly on film defects.

The appreciable increasing of all critical magnetic fields at cryogenic temperatures as compared with room temperature values applies to the field of sloped domain appearance, too. Its considerable value - about $2.5 \mathrm{Oe}$ - much more than the possible experimental error, demonstrates unambiguously the threshold nature of sloped domains appearance both at low and at room temperatures.

The research described in this publication was made possible in part by Grant No.M6Q300 from International Science Foundation.

\section{References}

[1] Korsun A.E., Lebedev S.V., Pankratov K.O., "Low Field Magnetizing of Epitaxial Garnet Film with InPlaneAnisotropy", Digest Book of the 6-th International Conference on Ferrites (ICF-6), Main Conf.: Sept.29 - Oct.2 1992, Tokyo, Japan, p.149.

[2] Korsun A.E., Lebedev S.V., Pankratov K.O., "The Influence of External Magnetic Fields on Hysteresis of Epitaxial Garnet Films with In-Plane Anisotropy", Digest Book of the 6-th International Conference on Ferrites (ICF-6), Satellite Conf: Oct. 5 - Oct. 7 1992, Kyoto, Japan, p.65.

[3] Lebedev S.V., "Detailed Investigation of Longitudinal Hysteresis of In-Plane Anisotropic Garnet Film by Room and Cryogenic Temperatures", Digest Book of 14-th International Colloquimum on Magnetic Films and Surfaces (ICMFS/EMRS'94), Dusseldorf, Germany, 1994, p.689-690.

[4] Esikov O.S., Protasov E.A., Pis'ma J.Tekh.Fys., 15 (1989), No.20, pp.11-14 (in Russian).

[5] Beljaeva A.I., Voicenja S.V., Yurjev V.P., Sverhprov.: fiz., him., tehn., 4 (1991), No.3, pp.507-510 (in Russian). 